\title{
The Genetics of Autism Spectrum Disorders
}

\author{
John J.M. Connolly ${ }^{1}$ and Hakon Hakonarson ${ }^{1,2}$ \\ ${ }^{1}$ Center for Applied Genomics \\ The Children's Hospital of Philadelphia, Philadelphia \\ ${ }^{2}$ Department of Pediatrics, University of Pennsylvania School of Medicine, Philadelphia \\ USA
}

\section{Introduction}

Autism is a neurodevelopmental disorder of complex etiology and is amongst the most heritable of neuropsychiatric disorders while sharing genetic liability with other neurodevelopmental disorders such as intellectual disability (ID). Autism spectrum disorders (ASDs) are defined more broadly and include autism, Asperger syndrome, childhood disintegrative disorder and pervasive developmental disorder not otherwise specified. Under the Diagnostic and Statistical Manual of Mental Disorders, $4^{\text {th }}$ Edition Revised (DSM-IVTR), these disorders are grouped together with Rett syndrome ("Rett's disorder") as pervasive developmental disorders. However, Rett syndrome has a reportedly distinct pathophysiology, clinical course, and diagnostic strategy (Levy \& Schultz, 2009) and will likely be removed in the impending publication of DSM-V (APA, 2010). The new diagnostic manual will formally adopt the single diagnostic category "ASDs", which is used here. Reported prevalence rates for ASDs range from 20 (Newschaffer et al. 2007) to 116 (Baird et al., 2006) per 10,000 children, and vary in accordance with diagnostic, sampling, and screening criteria. The Centers for Disease Control and Prevention (CDC) suggest that in the United States, the prevalence of ASDs is 1 in 110 (1/70 in boys and 1/315 in girls) (ADDM, 2009). The three primary characteristics of ASDs are communication impairments, social impairments, and repetitive/stereotyped behaviors. The DSM-IVTR, ICD-10, and many other diagnostic instruments require impairment in each of these domains for a diagnosis of autistic disorder.

Within the last decade, a number of major technological developments have transformed our understanding of the genetic causes of autism, and the field continues to evolve rapidly. In this chapter, we will review three approaches to identifying genetic factors that contribute to the pathogenesis of ASDs: 1) common variants and genome-wide association studies (GWAS); 2) rare variants and copy number variation (CNV) studies, and 3) familial forms of autism and the role of next-generation sequencing (NGS) methods. Data from all three approaches underscores the conclusion that autism is a highly complex and heterogeneous disorder, involving a multifactorial etiology. Moreover, it is becoming increasingly apparent that autism is not a unitary disorder, and that the spectrum may consist of any number of different autisms that share similar symptoms or phenotypes. This conclusion has important implications for evaluation and treatment, which are discussed in the conclusion. 


\section{Heritability of ASDs}

Although Skuse (2007) cautions that heritability estimates of ASDs may have been skewed by the co-inheritance of (low) intelligence or other variables, there is little doubt that genetic factors play a key role in autism. In the most widely-cited twin study, Bailey et al. (1995) report that monozygotic twins are $92 \%$ concordant on a broad spectrum of cognitive or social abnormalities, compared with only $10 \%$ for dizygotic twins. Parents and siblings of individuals with ASDs often exhibit subsyndromal levels of impairment (Piven et al., 1997), and having an affected sibling is the single biggest risk factor for developing an ASD. In an analysis of 943,664 Danish children (Lauritsen et al., 2005), the strongest predictors of autism were siblings with ASDs, who conferred a 22-fold increased risk, while Fombonne (2005) suggested that this risk may be even greater.

\section{Early insight from Rett syndrome and fragile $X$}

Early efforts to identify the genetic causes of ASDs utilized linkage and association approaches. Linkage studies, more prominent in the 1980s and 1990s, typically focus on families or larger pedigrees and is well powered to identify rare genetic variants. The most common linkage approach is the affected sib-pair design (see O'Roak \& State, 2008), which examines the transmission of genomic segments through generations. Linkage studies helped define the locus containing FMR1, which is mutated in fragile $\mathrm{X}$ syndrome (e.g. Richards et al., 1991), and is a common cause of autism in fragile X syndrome, affecting $\sim 30 \%$ of children who are diagnosed with fragile X (Rogers et al., 2001; Harris et al., 2008). Similarly, this approach has been important to identifying MECP2 as the major cause of Rett syndrome (e.g. Curtis et al., 1993).

Association studies take the opposite approach, scanning the genome from the top down, with the goal of determining post-hoc whether identified variants are more or less common in affected individuals. Early association studies (i.e. pre HapMap) were complementary with the linkage approach, and in many designs, linkage primed target loci for this more fine-grained analysis. These early insights have played a significant role in shaping our current understanding of ASDs, and functional studies of FMR1 and MECP2 have highlighted the importance of synaptic dysfunction (Ramocki \& Zoghbi, 2008) as a unifying factor that could extend into the more common forms of autism. This is significant because it provides a means of linking neural correlates with genomic data, as well as related clinical phenotypes such as seizures and cognitive deficits (Hagerman et al., 2009). The Alzheimer's paradigm, which includes functional models of how molecular, biochemical, and neural systems interact is instructive in this regard (e.g. Cissé et al., 2011).

\section{Genome wide association and common variants}

Aside from notable successes with fragile $X$ and Rett syndrome, early linkage and association studies have been inconsistent in resolving more complex genetic correlates of ASDs, with candidate genes often not being replicated between studies. These challenges may in part accounted-for by their relatively low resolution, which makes it difficult to detect candidate loci other than those of major effect. In the past decade however, association studies have become increasingly more sophisticated, with the whole-genome approach, allowing us to examine thousands of individuals on a mass scale, using hundreds of thousands of markers. 
Genome-wide association studies (GWAS) examine the frequency of single nucleotide polymorphisms (SNPs) in cases versus control populations and can adopt either a casecontrol or family-based approach. The former allows researchers to avoid the often complex process of acquiring diagnostic/phenotype data from a patient's family, and can incorporate very large numbers of control datasets that may be more readily available. The latter controls for the often confounding phenomenon of population stratification, where variants more common to specific racial groups may either be erroneously identified as causal, or obscure actual causal variants. A major caveat with family-based designs is the often unfounded assumption that unaffected family members do not share causal variants.

GWAS test for common variants ( $>1 \%$ population frequency), with the assumption that ASDs are at least in part caused by the coinheritance of multiple risk variants, each of small individual effect (odds ratios between 1:1 and 1:5). This assumption is known as the common disease-common variant (CDCV) model (Risch and Merikangas, 1996).

A 2009 paper by Wang et al. (2009) from our laboratory was the first to identify common variants for ASDs on a genome-wide scale. We examined 780 families (3,101 individuals) with affected children, a second group of 1,204 affected individuals, and 6,491 controls, all of whom were of European ancestry. We identified six genetic markers on chromosome 5 in the $5 \mathrm{p} 14.1$ region that confirmed susceptibility to ASDs. The region straddles two genes, CDH9 and CDH10. Both genes encode type II classical cadherins, transmembrane proteins that promote cell adhesion. The association of cadherins is consistent with the corticaldisconnectivity model of autism (e.g. Gepner \& Féron, 2009), which postulates that ASDs may result from an increase or decrease in functional connectivity and neuronal synchronization in relevant neural pathways. Functional studies suggest that under-activity between and within networks are correlated with social, communication, cognitive, and sensorimotor impairments (Müller et al., 2011).

The study design utilized two independent replication cohorts and the key SNP at this locus has also been replicated in two additional independent cohort studies (Ma et al., 2009; St Pourcain et al., 2010), lending further support that genetic factors at the 5p14 locus, which is flanked by two relevant cadherin genes, represent strong candidates for aligning molecular function with known neural deficits in ASDS. The original report by Wang and colleagues, also demonstrated that there was an enrichment in Catherin associated genes in ASDs in general, based on gene-pathway analysis (Wang et al, 2009). Cadherins represent a large family of transmembrane proteins that mediates calcium-dependent cell-cell adhesion and, via cell adhesion, has been shown to generate synaptic complexity in the developing brain (Redies, 2000). Other common GWAS variants reported have not been replicated in independent studies and will not be covered here.

\subsection{Replicated common variants from candidate gene studies}

Other common variants from candidate gene studies include CNTNAP2, EN2, and MET, which are reviewed briefly below. A more in depth review of these genes can be derived from catalogs at http://www.genome.gov/26525384 and http://w w w.ncb.nlm.nih.gov/o $\mathrm{mim} / 209850$.

Located on chromosome 7q35, Contactin Associated Protein 2 (CNTNAP2) was identified by Alarcón et al. (2002) as a candidate for the age at first word endophenotype. A subsequent follow-up by the same group (Alarcón et al. 2008) using linkage, association, and geneexpression analyses, found CNTNAP2 to be the only autism-susceptibility gene to reach significance across all approaches. An independent linkage analysis by Arking et al. (2008) also highlighted CNTNAP2 as a significant ASD candidate gene. CNTNAP2 is part of the 
neurexin family, which have repeatedly been associated with autism (see below). Interestingly, Vernes et al. (2008) showed that CNTNAP2 binds to FOXP2, which is a wellestablished correlate of language and speech disorders (Lai et al., 2001) - a common phenotype in ASDs.

Engrailed 2 (EN2) is a homeobox gene that is critical to the development of the midbrain and cerebellum. Like other homeobox genes, it regulates morphogenesis. EN2 is a human homolog of the engrailed gene, which is found in Drosophila. En2 mouse mutants have anatomic phenotypes in the cerebellum that resemble cerebellar abnormalities reported in autistic individuals (Cheng et al., 2010). Benayed et al. $(2005,2009)$ have reported and replicated in three separate datasets a significant association with broad and narrow ASD phenotypes. Wang et al. (2008) also found an association between EN2 and ASDs in a Chinese Han sample, although Zhong et al. (2003) failed to find evidence of an underlying association.

The oncogene MET is also strongly linked to ASD etiology, having been supported by a number of studies in the past decade (e.g. IMGSAC, 2001; Campbell et al., 2006, 2008; Sousa et al., 2009). Recently, Eagleson et al. (2011) reported a role for Met signaling in cortical interneuron development in vitro in a mouse model.

\subsection{Unexplained variance}

For the most significant discovery SNP identified in the Wang et al. study above (rs4307059), the risk allele frequency was 0.65 in cases with an odds ratio of 1.19 , which is comparable with common variant discoveries in other psychiatric disorders including schizophrenia (Glessner \& Hakonarson, 2009; Glessner et al., 2010); bipolar disorder (Ferreira, 2008), and attention-deficit/hyperactivity disorder (Arcos-Burgos et al. 2010). While it is important not to undermine the significance of these findings, it should be noted that the predictive value of such ratios is relatively low (Dickson et al. 2010), often explaining less than $5 \%$ of the total risk (review at http://www.genome.gov/26525384). However, it is also possible that these common SNPs may be tagging a more rare causative variant (i.e., synthetic association), where the effect sizes may be markedly underestimated by the GWAS variant as we recently reported (Dickson et al. 2010). In one example, Wang et al. (2010), examined the NOD2 locus as a cause of Crohn disease. Using resequencing data, they found that three causal variants explain $>5 \%$ of the genetic risk, where GWAS had estimated the risk at $\sim 1 \%$. Careful phenotyping of cohorts is important to ensure that the phenotypes produced by rarevariants are not being "filtered-out" and thereby missed as a consequence. A long range haplotype analysis of the GWAS data at the respective loci is therefore recommended in an attempt to enrich for individuals with rare-causative variants, who should be picked out of the cohort and subsequently sequenced for confirmation (Wang et al., 2010). This is clearly a critical point, particularly in relation to psychiatric disorders, where diagnoses can be more contingent upon subjective observation than, for example, the genetics of height, which can utilize more intrinsically quantitative data.

The possibility that common variants are not the major cause of ASDs is also gaining increased support from the preponderance of copy number variation (CNV) studies, which are identifying rare variants with a stronger causal impact.

\section{Copy number variation in ASDs}

Copy number variations (CNVs) are insertions, deletions, or translocations in the human genome that are universal in the general population but more commonly found in genic 
regions in individuals with neuropsychiatric disorders (e.g. Pinto et al., 2010). CNVs can be detected by the same SNP arrays used in GWAS, and vary in length from many megabases to 1 kilobase or smaller. They are often not associated with any observable phenotype.

One of the most widely-known CNVs is Down syndrome, which is characterized by an extra chromosome 21 . Rett syndrome is also caused by a CNV, which includes a deletion in MECP2. CNVs can be inherited or occur de novo, the cause of which is thus far unknown. Common disease-causing CNVs are infrequent but rare CNVs, with a frequency of less than $1 \%$, have been identified for a range of disorders including ADHD (e.g. Williams et al., 2010), schizophrenia (e.g. Glessner et al., 2010; Levinson et al., 2011), bipolar disorder (e.g. Chen et al., 2010) and many others. A substantial portion of autism appears to be caused by rare CNVs. De novo CNVs that are greater than $100 \mathrm{~kb}$ in size are more common in genic regions in individuals with ASDs than in the general population.

Sebat et al. (2007) provided some relevant early insights into the genomic features of CNVs. Firstly, they noted that de novo CNVs were individually rare - from 118 ASD cases, none of the identified variants were observed more than twice, with the majority seen just once. This confirmed the widely-held assumption that many different loci can contribute to the same ASD phenotype. Secondly, the authors affirmed the utility of population-study approaches that analyze sporadic and multiplex (i.e. more than one family member affected) families separately. The rate of de novo mutation in large (mostly genic) loci in multiplex families was significantly lower than for the sporadic cases $(p=0.04)$. While this observation remains to be replicated in a larger study, the finding implies two mechanisms of genetic susceptibility - spontaneous mutation and inheritance. Finally, the sheer volume of loci identified by this approach (multiple loci on 20 chromosomes) affirms the extraordinarily complexity of ASDs.

A number of subsequent studies have greatly expanded the number of candidate loci. Our laboratory (Bucan et al. (2009)) reported 150+ CNVs in 912 ASD families that were not found in 1,488 controls. Critically, 27 of these loci were replicated in an independent cohort of 859 ASD cases and 1,051 controls. Some of the rare variants we identified had previously been associated with autism, including NRXN1 and UBE3A, which are established ASD candidate genes (Guilmatre et al., 2009). Samaco et al. (2005) previously identified significant deficits in ube3a expression in mecp2-deficient mice, suggesting a shared pathological pathway with Rett syndrome (as well as Angelman syndrome, and autism). Similarly, Kim et al. (2008) associated NRXN1 with a balanced chromosomal abnormality at chromosome 2p16.3 in two unrelated ASD individuals. Rare variants in the coding region included two missense changes.

Glessner et al. (2009) identified and reported CNVs in two major gene networks, including neuronal cell adhesion molecules (such as NRXN1) and the ubiquitin gene family (such as $U B E 3 A$ ). Interestingly, four of the most prominent genes enriched by CNVs in ASD cases (UBE3A, PARK2, RFWD2 and FBXO40) are all part of the ubiquitin gene family. Ubiquitination can alter protein function after translation, and degrade target proteins in conjunction with proteasomes. The ubiquitin-proteasome system operates at pre- and postsynapses, whose functions includes regulating neurotransmitter release, recycling synaptic vesicles in pre-synaptic terminals, and modulating changes in dendritic spines and postsynaptic density (Yi \& Ehlers, 2005). As well as implicating an ubiquitination network in relation to ASDs, we also identified a second pathway involving NRXN1, CNTN4, NLGN1, and ASTN2. Genes in this group mediate neuronal cell-adhesion, and contribute to neurodevelopment by facilitating axon guidance, synapse formation and plasticity, and neuron-glial interactions. We also note that ubiquitins are involved in recycling cell- 
adhesion molecules, which is a possible mechanism by which these two networks are cross linked.

In a similar approach, Pinto et al. (2010) further confirmed the importance of rare CNVs as causal factors for ASDs. Interestingly, the group did not observe a significant difference between cases and controls in terms of raw number of CNVs or estimated CNV size. However, the number of CNVs in genic regions was significantly greater in ASDs compared to controls. Again, loci enriched for $\mathrm{CNV}$ s include a number of genes known to be important for neurodevelopment and synaptic plasticity, such as SHANK2, SYNGAP1, and DLGAP2. Between $5.5 \%$ and $5.7 \%$ of ASD cases have at least one de novo $\mathrm{CNV}$, further confirming the significance of de novo genetic events as risk factors for autism. Similar to the Glessner study, the Pinto group mapped CNVs to a series of networks involved in the development and regulation of the central nervous system functions. Implicated networks include neuronal cell adhesion, GTPase regulation (important for signal transduction and biosynthesis), and GTPase/Ras signaling, also involved in ubiquitination.

Finally, Gai et al. (2011) took a slightly different approach, focusing exclusively on inherited CNVs. While underlying loci were not necessarily common to those identified by the Glessner and Pinto groups, enrichment in pathways involving central nervous system development, synaptic functions and neuronal signaling processes was again confirmed. The Gai et al. study also emphasized the role of glutamate-mediated neuronal signals in ASDs.

Collectively, these CNV studies suggest that certain hotspots on the genome are particularly vulnerable to ASDs, which include loci on chromosomes 1q21, 3p26, 15q11-q13, 16p11, and 22q11. These hotspots are part of large gene networks that are important to neural signaling and neurodevelopment and have additionally been associated with other neuropsychiatric disorders.

In particular, a number of $\mathrm{CNV}$ studies in schizophrenia have highlighted structural mutations incorporating chromosomes 1q21, 15q13, and 22q11 (e.g. McClellan and King 2010; Glessner et al., 2010), which are significantly enriched in cases versus controls, with NRXN1 being a standout in this regard. From a phenotype perspective, autism and schizophrenia seem very different, both in behavioral manifestation and age of onset, and it may seem counter-intuitive that associated loci should overlap. Some authors have addressed this peculiarity by proposing that schizophrenia and autism may in fact be different poles of the same spectrum. Thus, Crespi and Braddock (2008) suggest that social cognition is underdeveloped in ASDs and over-developed in the psychotic spectrum, with a similar polarization of language and behavioral phenotypes. Although speculative, this hypothesis has gained some traction. In the next several years, genomic, imaging, and model-systems approaches will likely shed further light on the relationship between autism, schizophrenia and other neuropsychiatric disorders.

\section{Sequencing familial forms of ASDs}

To this point, we have focused primarily on the complex interactions of polygenic networks as the major cause of ASDs. However, this is not exclusively the case. Paralleling the recent spate of $\mathrm{CNV}$ is a renewed focus on rare disorders, including familial forms of complex diseases that potentially are monogenic or with less complex inheritance pattern. At the outset of this chapter, we emphasized the overlap with fragile $X$ syndrome, where one third of cases are co-morbid for ASD. As mentioned, fragile $X$ is caused by a failure to express the 
protein coded by FMR1. However, mutations in FMR1 do not always result in fragile- $\mathrm{X}$ and can result in a phenotype more representative of ASDs. Thus, Muhle et al. (2004) found that $7-8 \%$ of idiopathic ASD cases may have mutations at the FMR1 locus. Likewise, although mutations in $M E C P 2$ are the common cause of Rett syndrome, certain mutations at the same locus have been associated with idiopathic autism (Carney et al. (2003).

X-linked genes encoding neurologins NLGN3 and NLGN4 and SHANK3 (a neuroligin binding partner) are other prominent examples of distinct rare genetic causes, and a parallel can be drawn with these studies and mental retardation and epilepsy, which include many rare syndromes that collectively account for a substantial proportion of the two disorders (Morrow et al., 2008). Indeed it is perhaps more than coincidence that autism is heavily comorbid with these two conditions, with $>40 \%$ ( Bölte et al., 2009) and $\sim 40 \%$ (Danielsson et al., 2005) of ASD cases meeting diagnostic criteria for mental retardation and epilepsy respectively. It also is noteworthy that many of these monogenic-related genes are also major players in neurodevelopment and synapse activity. Other prominent examples include TSC1, TSC2 (Osborne et al., 1991; Franz, 1998), NF1, and UBE3A (see Morrow et al. (2008).

The identification of monogenic or possibly oligogenic autisms is likely to accelerate in the next several years as next-generation sequencing becomes more widely available. We recently encountered a family of two parents, six healthy siblings, and two siblings with severe autism suggestive of autosomal recessive inheritance. Unsuccessful attempts using linkage and CNV approaches failed to identify a causal locus, but whole-exome sequencing at 20x coverage identified four genes, including one with a non-synonymous SNP in the protocadherin alpha 4 isoform1 precursor (PCDHA4) gene, which presents a strong candidate gene, currently under validation. Protocadherins are part of the cadherin family that facilitates neuronal cell adhesion and this discovery is consistent genomically and neurobiologically with the findings addressed above in relation to $\mathrm{CDH}$ and $\mathrm{CDH} 10$.

Known syndromes with ASD features include fragile-x, neurofibromatosis type 1, down syndrome, tuberous sclerosis, neurofibromatosis (which confers a 100-fold increased risk for ASDs Li et al. (2005), Angelman, Prader-Willi and related 15q syndromes, and at least several dozen others (see Zafeiriou et al., 2007 for a comprehensive review). Table 1 from Volkmar et al. (2005) lists the most commonly associated syndromes with median rate and range. It is likely that many more unidentified rare syndromes with Mendelian causes have ASD phenotypes. As of March 2011, the Online Mendelian Inheritance in Man (OMIM) database listed 6,727 known or suspected Mendelian diseases (MD), with 2,993 (44\%) of these having an identified molecular basis. Since OMIM derives its data from published reports, these figures likely under-represent rare disorders, which may go unreported. It has been proposed that as many as 30,000 genetic disorders may exist, suggesting that many Mendelian disorders have no genetic etiology identified to date. Given the largerepresentation of autism phenotypes in known syndromes, we can assume a similar trend in unreported disease.

It remains to be determined whether rare variants will account for the majority of autisms. Irrespective, as with many other aspects of scientific inquiry, the study of rare variants will continue to play an important role in explicating the pathogenesis of ASDs. El-Fishawy and State (2010) point to hypercholesterolemia and hypertension (Brown, 1974; Lifton et al., 2001) as examples where rare mutations have been successful in driving a molecular understanding of the disease as opposed to identifying risk factors in the general 
population. Rare mutations, particularly when they are Mendelian, carry large effects and are typically in genic regions. These characteristics make the resolution of underlying networks distinctly less complex and, moreover, are amenable to modeling in other systems. Recent groundbreaking studies by Marchetto et al. (2010) and Muotri et al. (2010), who created a cell culture model of Rett syndrome, are potentially exciting developments in this regard. Here, the researchers used skin biopsies from four Rett's patients, each carrying a different $\mathrm{MeCP} 2$ mutation, to culture induced pluripotent stem cells (iPS). Once the iPS cells developed into neurons, they showed a decreased number of neurons and dendritic spines, consistent with neurodevelopmental disruptions. Intervention with insulin-like growth factor 1 (IGF1), which is known to regulate neurodevelopment, was subsequently shown to reverse Rett-like symptoms in a mouse model of the disease. This innovative approach is an exciting model of how rare gene approaches can stimulate our understanding of the pathophysiology and potential reversibility of ASDs.

\begin{tabular}{lccc}
\hline Syndrome & Number of Studies & Median Rate & Range \% \\
\hline Tuberous sclerosis & 11 & 1.1 & $0-3.8$ \\
Fragile X & 9 & 0.0 & $0-8.1$ \\
Down syndrome & 12 & 0.7 & $0-16.7$ \\
Neurofibromatosis 1 & 6 & 0 & $0-1.4$ \\
\hline
\end{tabular}

Table 1. Associated disorders and their rate in autism (from Volkmar et al., 2005 in Zafeiriou et al. 2007)

\section{Conclusions}

ASDs are clearly highly heritable disorders and advances in gene-finding technology in the past decade have rapidly accelerated gene discovery. As is typically the case, successive developments have made the problem more complex such that there are dozens of candidate genes, many of which remain to be replicated. In spite of this complexity, we can observe a number of patterns beginning to unfold 1) the relative scarcity of causal common variants, 2) the growing list of causal rare variants, and 3) the emergence of monogenic disorders with primary and secondary ASD phenotypes.

The monogenic autisms are particularly interesting from a treatment perspective, as they provide a mechanism for studying ASD phenotypes in model systems and an obvious target for drug intervention. They are also amenable to clinical testing and the decreasing cost of research technologies means that this capacity is more widely available to clinicians. In fact, as the resolution of clinical instruments becomes more sophisticated, it is likely that the clinic will become a primary workplace for syndromic discovery.

A key requirement in driving gene discovery is the necessity of high-quality phenotype data. ASDs are notoriously heterogeneous, and are fractionated in terms of symptoms and trajectory. Mandy \& Skuse (2008) reviewed seven factor analysis studies of ASDs symptoms, and found that all but one dissociated social and non-social factors. In a non-clinical sample of 3,000 twin pairs, Happé et al. (2006) examined autistic-like traits and found consistently low correlations $(r=0.1-0.4)$ between each of the core deficits on the autism spectrum. Endophenotypes, sub-components or sub-processes of the broader phenotype, may provide a productive avenue to disentangling some of this complexity. By filtering out all but a few discrete measures, we can theoretically increase the signal-to-noise ratio in genotypephenotype associations. A number of endophenotypes for ASDs have been identified 
associated with disease genes, including head circumference (associated with the HOXA1 A218G polymorphism, Conciatori et al., 2004), age at first word (associated with a quantitative trait locus on 7q35, Alarcón et al. 2005), delayed magnetoencephalography evoked responses to auditory stimuli (Roberts et al., 2010), and enhanced perception (Mottron et al., 2006). The endophenotype approach is arguably more consistent with rare/mono-genic discovery, where a mutated network may not yield a diagnosis of autism per $s e$, but nevertheless cause associated abnormalities. Note, this approach does not diminish the pleiotropic effects of genes involved in neurodevelopment, and only serves to make the point that the relevant genotype may associate with some but not all ASD features.

The converse, of course, is also true with a large number of candidate genes contributing to the majority of known ASDs. With $\sim 80 \%$ of genes expressed in the brain it is likely that this number will continue to grow, and here again careful phenotyping is critical to identifying functional consequences. Ultimately, the primary goal is not to determine the frequency of variation/mutation in cases versus controls, but to determine the pathway(s) and gene networks that lead to pathology. This will be no mean feat, with other major players such as epigenetic factors, RNA regulatory elements, and environmental exposures also an important part of the equation. While daunting, the elucidation of these elements will doubtlessly take us closer to developing effective treatments for ASDs. Given the current rate of progress, we have cause for cautious optimism in this regard.

\section{References}

Alarcon, M., Abrahams, B. S., Stone, J. L., Duvall, J. A., Perederiy, J. V., Bomar, J. M., Geschwind, D. H. (2008). Linkage, association, and gene-expression analyses identify CNTNAP2 as an autism-susceptibility gene. Am J Hum Genet, 82(1), 150159. doi: 10.1016/j.ajhg.2007.09.005

Alarcon, M., Yonan, A. L., Gilliam, T. C., Cantor, R. M., \& Geschwind, D. H. (2005). Quantitative genome scan and Ordered-Subsets Analysis of autism endophenotypes support language QTLs. Mol Psychiatry, 10(8), 747-757. doi: 10.1038/sj.mp.4001666

Alarcon, M., Cantor, R. M., Liu, J., Gilliam, T. C., \& Geschwind, D. H. (2002). Evidence for a language quantitative trait locus on chromosome $7 \mathrm{q}$ in multiplex autism families. Am J Hum Genet, 70(1), 60-71. doi: 10.1086/338241

Arcos-Burgos, M., Jain, M., Acosta, M. T., Shively, S., Stanescu, H., Wallis, D., Muenke, M. (2010). A common variant of the latrophilin 3 gene, LPHN3, confers susceptibility to ADHD and predicts effectiveness of stimulant medication. Mol Psychiatry, 15(11), 1053-1066. doi: 10.1038/mp.2010.6

American Psychiatric Association, (2010, March 22, 2010). New Proposed Changes Posted for Leading Manual of Mental Disorders. Retrieved from http://www.dsm5.org/Pages/Default.aspx

Arking, D. E., Cutler, D. J., Brune, C. W., Teslovich, T. M., West, K., Ikeda, M., Chakravarti, A. (2008). A common genetic variant in the neurexin superfamily member CNTNAP2 increases familial risk of autism. Am J Hum Genet, 82(1), 160-164. doi: 10.1016/j.ajhg.2007.09.015

Autism and Developmental Disabilities Monitoring Network Surveillance Year 2006 (2009). Prevalence of autism spectrum disorders-Autism and Developmental Disabilities 
Monitoring Network MMWR Surveillence Summary, 58, 1-20. United States, 2006: Centers for Disease Control and Prevention.

Bailey, A., Le Couteur, A., Gottesman, I., Bolton, P., Simonoff, E., Yuzda, E., \& Rutter, M. (1995). Autism as a strongly genetic disorder: evidence from a British twin study. Psychol Med, 25(1), 63-77.

Baird, G., Simonoff, E., Pickles, A., Chandler, S., Loucas, T., Meldrum, D., \& Charman, T. (2006). Prevalence of disorders of the autism spectrum in a population cohort of children in South Thames: the Special Needs and Autism Project (SNAP). Lancet, 368(9531), 210-215. doi: 10.1016/s0140-6736(06)69041-7

Benayed, R., Choi, J., Matteson, P. G., Gharani, N., Kamdar, S., Brzustowicz, L. M., \& Millonig, J. H. (2009). Autism-associated haplotype affects the regulation of the homeobox gene, ENGRAILED 2. Biol Psychiatry, 66(10), 911-917. doi: 10.1016/j.biopsych.2009.05.027

Benayed, R., Gharani, N., Rossman, I., Mancuso, V., Lazar, G., Kamdar, S., . Millonig, J. H. (2005). Support for the homeobox transcription factor gene ENGRAILED 2 as an autism spectrum disorder susceptibility locus. Am J Hum Genet, 77(5), 851-868. doi: $10.1086 / 497705$

Bolte, S., Dziobek, I., \& Poustka, F. (2009). Brief report: The level and nature of autistic intelligence revisited. J Autism Dev Disord, 39(4), 678-682. doi: 10.1007/s10803-0080667-2

Brown, M. S., \& Goldstein, J. L. (1974). Expression of the familial hypercholesterolemia gene in heterozygotes: mechanism for a dominant disorder in man. Science, 185(4145), 61-63.

Bucan, M., Abrahams, B. S., Wang, K., Glessner, J. T., Herman, E. I., Sonnenblick, L. I., Hakonarson, H. (2009). Genome-wide analyses of exonic copy number variants in a family-based study point to novel autism susceptibility genes. PLoS Genet, 5(6), e1000536. doi: 10.1371/journal.pgen.1000536

Campbell, D. B., Li, C., Sutcliffe, J. S., Persico, A. M., \& Levitt, P. (2008). Genetic evidence implicating multiple genes in the MET receptor tyrosine kinase pathway in autism spectrum disorder. Autism Res, 1(3), 159-168. doi: 10.1002/aur.27

Campbell, D. B., Sutcliffe, J. S., Ebert, P. J., Militerni, R., Bravaccio, C., Trillo, S., . . Levitt, P. (2006). A genetic variant that disrupts MET transcription is associated with autism. Proc Natl Acad Sci U S A, 103(45), 16834-16839. doi: 10.1073/pnas.0605296103

Carney, R. M., Wolpert, C. M., Ravan, S. A., Shahbazian, M., Ashley-Koch, A., Cuccaro, M. L., ... Pericak-Vance, M. A. (2003). Identification of MeCP2 mutations in a series of females with autistic disorder. Pediatr Neurol, 28(3), 205-211.

Chen, X., Li, X., Wang, P., Liu, Y., Zhang, Z., Zhao, G., Kong, X. (2010). Novel association strategy with copy number variation for identifying new risk Loci of human diseases. PLoS One, 5(8), e12185. doi: 10.1371/journal.pone.0012185

Cheng, Y., Sudarov, A., Szulc, K. U., Sgaier, S. K., Stephen, D., Turnbull, D. H., \& Joyner, A. L. (2010). The Engrailed homeobox genes determine the different foliation patterns in the vermis and hemispheres of the mammalian cerebellum. Development, 137(3), 519-529. doi: 10.1242/dev.027045

Cisse, M., Halabisky, B., Harris, J., Devidze, N., Dubal, D. B., Sun, B., Mucke, L. (2011). Reversing EphB2 depletion rescues cognitive functions in Alzheimer model. Nature, 469(7328), 47-52. doi: 10.1038/nature09635 
Conciatori, M., Stodgell, C. J., Hyman, S. L., O'Bara, M., Militerni, R., Bravaccio, C., .Persico, A. M. (2004). Association between the HOXA1 A218G polymorphism and increased head circumference in patients with autism. Biol Psychiatry, 55(4), 413-419. doi: 10.1016/j.biopsych.2003.10.005

Crespi, B., \& Badcock, C. (2008). Psychosis and autism as diametrical disorders of the social brain. Behav Brain Sci, 31(3), 241-261; discussion 261-320. doi: 10.1017/s0140525x08004214

Curtis, A. R., Headland, S., Lindsay, S., Thomas, N. S., Boye, E., Kamakari, S., et al. (1993). X chromosome linkage studies in familial Rett syndrome. Hum Genet, 90(5), 551-555.

Danielsson, S., Gillberg, I. C., Billstedt, E., Gillberg, C., \& Olsson, I. (2005). Epilepsy in young adults with autism: a prospective population-based follow-up study of 120 individuals diagnosed in childhood. Epilepsia, 46(6), 918-923. doi: 10.1111/j.15281167.2005.57504.x

Dickson, S. P., Wang, K., Krantz, I., Hakonarson, H., \& Goldstein, D. B. (2010). Rare variants create synthetic genome-wide associations. PLoS Biol, 8(1), e1000294. doi: 10.1371/journal.pbio.1000294

Eagleson, K. L., Campbell, D. B., Thompson, B. L., Bergman, M. Y., \& Levitt, P. (2011). The autism risk genes MET and PLAUR differentially impact cortical development. Autism Res, 4(1), 68-83. doi: 10.1002/aur.172

El-Fishawy, P., \& State, M. W. (2010). The genetics of autism: key issues, recent findings, and clinical implications. Psychiatr Clin North Am, 33(1), 83-105. doi: 10.1016/j.psc.2009.12.002

Ferreira, M. A., O'Donovan, M. C., Meng, Y. A., Jones, I. R., Ruderfer, D. M., Jones, L., Craddock, N. (2008). Collaborative genome-wide association analysis supports a role for ANK3 and CACNA1C in bipolar disorder. Nat Genet, 40(9), 1056-1058. doi: 10.1038/ng.209

Fombonne, E. (2009). Epidemiology of pervasive developmental disorders. Pediatr Res, 65(6), 591-598. doi: 10.1203/PDR.0b013e31819e7203

Franz, D. N. (1998). Diagnosis and management of tuberous sclerosis complex. Semin Pediatr Neurol, 5(4), 253-268.

Gai, X., Xie, H. M., Perin, J. C., Takahashi, N., Murphy, K., Wenocur, A. S., .White, P. S. (2011). Rare structural variation of synapse and neurotransmission genes in autism. Mol Psychiatry. doi: 10.1038/mp.2011.10

Gepner, B., \& Feron, F. (2009). Autism: a world changing too fast for a mis-wired brain? Neurosci Biobehav Rev, 33(8), 1227-1242. doi: 10.1016/j.neubiorev.2009.06.006

Glessner, J. T., \& Hakonarson, H. (2009). Common variants in polygenic schizophrenia. Genome Biol, 10(9), 236. doi: 10.1186/gb-2009-10-9-236

Glessner, J. T., Reilly, M. P., Kim, C. E., Takahashi, N., Albano, A., Hou, C., Hakonarson, H. (2010). Strong synaptic transmission impact by copy number variations in schizophrenia. Proc Natl Acad Sci U S A, 107(23), 10584-10589. doi: 10.1073/pnas.1000274107

Glessner, J. T., Wang, K., Cai, G., Korvatska, O., Kim, C. E., Wood, S., Hakonarson, H. (2009). Autism genome-wide copy number variation reveals ubiquitin and neuronal genes. Nature, 459(7246), 569-573. doi: 10.1038/nature07953

Guilmatre, A., Dubourg, C., Mosca, A. L., Legallic, S., Goldenberg, A., Drouin-Garraud, V., Campion, D. (2009). Recurrent rearrangements in synaptic and 
neurodevelopmental genes and shared biologic pathways in schizophrenia, autism, and mental retardation. Arch Gen Psychiatry, 66(9), 947-956. doi: 10.1001/archgenpsychiatry.2009.80

Hagerman, R. J., Berry-Kravis, E., Kaufmann, W. E., Ono, M. Y., Tartaglia, N., Lachiewicz, A., Tranfaglia, M. (2009). Advances in the treatment of fragile $X$ syndrome. Pediatrics, 123(1), 378-390. doi: 10.1542/peds.2008-0317

Happe, F., Ronald, A., \& Plomin, R. (2006). Time to give up on a single explanation for autism. Nat Neurosci, 9(10), 1218-1220. doi: 10.1038/nn1770

Harris, S. W., Hessl, D., Goodlin-Jones, B., Ferranti, J., Bacalman, S., Barbato, I., Hagerman, R. J. (2008). Autism profiles of males with fragile X syndrome. Am J Ment Retard, 113(6), 427-438.

International Molecular Genetic Study of Autism Consortium (IMGSAC). A genomewide screen for autism: strong evidence for linkage to chromosomes $2 \mathrm{q}, 7 \mathrm{q}$, and $16 \mathrm{p}$. (2001). Am J Hum Genet, 69(3), 570-581. doi: 10.1086/323264

Kim, H. G., Kishikawa, S., Higgins, A. W., Seong, I. S., Donovan, D. J., Shen, Y., Gusella, J. F. (2008). Disruption of neurexin 1 associated with autism spectrum disorder. Am J Hum Genet, 82(1), 199-207. doi: 10.1016/j.ajhg.2007.09.011

Lai, C. S., Fisher, S. E., Hurst, J. A., Vargha-Khadem, F., \& Monaco, A. P. (2001). A forkheaddomain gene is mutated in a severe speech and language disorder. Nature, 413(6855), 519-523. doi: 10.1038/35097076

Lauritsen, M. B., Pedersen, C. B., \& Mortensen, P. B. (2005). Effects of familial risk factors and place of birth on the risk of autism: a nationwide register-based study. J Child Psychol Psychiatry, 46(9), 963-971. doi: 10.1111/j.1469-7610.2004.00391.x

Levinson, D. F., Duan, J., Oh, S., Wang, K., Sanders, A. R., Shi, J., Gejman, P. V. (2011). Copy Number Variants in Schizophrenia: Confirmation of Five Previous Findings and New Evidence for 3q29 Microdeletions and VIPR2 Duplications. Am J Psychiatry, 168(3), 302-316. doi: 10.1176/appi.ajp.2010.10060876

Levy, S. E., Mandell, D. S., \& Schultz, R. T. (2009). Autism. Lancet, 374(9701), 1627-1638. doi: 10.1016/s0140-6736(09)61376-3

Li, W., Cui, Y., Kushner, S. A., Brown, R. A., Jentsch, J. D., Frankland, P. W., Silva, A. J. (2005). The HMG-CoA reductase inhibitor lovastatin reverses the learning and attention deficits in a mouse model of neurofibromatosis type 1. Curr Biol, 15(21), 1961-1967. doi: 10.1016/j.cub.2005.09.043

Lifton, R. P., Gharavi, A. G., \& Geller, D. S. (2001). Molecular mechanisms of human hypertension. Cell, 104(4), 545-556.

Ma, D., Salyakina, D., Jaworski, J.M., Konidari, I., Whitehead, P.L., Andersen, A.N., ...Pericak-Vance MA (2009). Ann. Hum. Genet. 73, 263-273.

Mandy, W. P., \& Skuse, D. H. (2008). Research review: What is the association between the social-communication element of autism and repetitive interests, behaviours and activities? J Child Psychol Psychiatry, 49(8), 795-808. doi: 10.1111/j.14697610.2008.01911.x

Marchetto, M. C., Carromeu, C., Acab, A., Yu, D., Yeo, G. W., Mu, Y., Muotri, A. R. (2010). A model for neural development and treatment of Rett syndrome using human induced pluripotent stem cells. Cell, 143(4), 527-539. doi: 10.1016/j.cell.2010.10.016

McClellan, J., \& King, M. C. (2010). Genetic heterogeneity in human disease. Cell, 141(2), $210-$ 217. doi: $10.1016 /$ j.cell.2010.03.032 
Morrow, E. M., Yoo, S. Y., Flavell, S. W., Kim, T. K., Lin, Y., Hill, R. S., Walsh, C. A. (2008). Identifying autism loci and genes by tracing recent shared ancestry. Science, 321(5886), 218-223. doi: 10.1126/science.1157657

Mottron, L., Dawson, M., Soulieres, I., Hubert, B., \& Burack, J. (2006). Enhanced perceptual functioning in autism: an update, and eight principles of autistic perception. $J$ Autism Dev Disord, 36(1), 27-43. doi: 10.1007/s10803-005-0040-7

Muhle, R., Trentacoste, S. V., \& Rapin, I. (2004). The genetics of autism. Pediatrics, 113(5), e472-486.

Muller, R. A., Shih, P., Keehn, B., Deyoe, J. R., Leyden, K. M., \& Shukla, D. K. (2011). Underconnected, but How? A Survey of Functional Connectivity MRI Studies in Autism Spectrum Disorders. Cereb Cortex. doi: 10.1093/cercor/bhq296

Muotri, A. R., Marchetto, M. C., Coufal, N. G., Oefner, R., Yeo, G., Nakashima, K., \& Gage, F. H. (2010). L1 retrotransposition in neurons is modulated by MeCP2. Nature, 468(7322), 443-446. doi: 10.1038/nature09544

Newschaffer, C. J., Croen, L. A., Daniels, J., Giarelli, E., Grether, J. K., Levy, S. E., . Windham, G. C. (2007). The epidemiology of autism spectrum disorders. Annu Rev Public Health, 28, 235-258. doi: 10.1146/annurev.publhealth.28.021406.144007

O'Roak, B. J., \& State, M. W. (2008). Autism genetics: strategies, challenges, and opportunities. Autism Res, 1(1), 4-17. doi: 10.1002/aur.3

Osborne, J. P., Fryer, A., \& Webb, D. (1991). Epidemiology of tuberous sclerosis. Ann N Y Acad Sci, 615, 125-127.

Pinto, D., Pagnamenta, A. T., Klei, L., Anney, R., Merico, D., Regan, R., Betancur, C. (2010). Functional impact of global rare copy number variation in autism spectrum disorders. Nature, 466(7304), 368-372. doi: 10.1038/nature09146

Piven, J., Palmer, P., Jacobi, D., Childress, D., \& Arndt, S. (1997). Broader autism phenotype: evidence from a family history study of multiple-incidence autism families. Am J Psychiatry, 154(2), 185-190.

Ramocki, M. B., \& Zoghbi, H. Y. (2008). Failure of neuronal homeostasis results in common neuropsychiatric phenotypes. Nature, 455(7215), 912-918. doi: 10.1038/nature07457

Redies, C. (2000). Cadherins in the central nervous system. Prog Neurobiol, 61(6), 611-648.

Richards, R. I., Holman, K., Kozman, H., Kremer, E., Lynch, M., Pritchard, M., Sutherland, G. R. (1991). Fragile X syndrome: genetic localisation by linkage mapping of two microsatellite repeats FRAXAC1 and FRAXAC2 which immediately flank the fragile site. J Med Genet, 28(12), 818-823.

Risch, N., \& Merikangas, K. (1996). The future of genetic studies of complex human diseases. Science, 273(5281), 1516-1517.

Roberts, T. P., Khan, S. Y., Rey, M., Monroe, J. F., Cannon, K., Blaskey, L., .Edgar, J. C. (2010). MEG detection of delayed auditory evoked responses in autism spectrum disorders: towards an imaging biomarker for autism. Autism Res, 3(1), 8-18. doi: 10.1002/aur.111

Rogers, S. J., Wehner, D. E., \& Hagerman, R. (2001). The behavioral phenotype in fragile X: symptoms of autism in very young children with fragile $X$ syndrome, idiopathic autism, and other developmental disorders. J Dev Behav Pediatr, 22(6), 409-417.

Samaco, R. C., Hogart, A., \& LaSalle, J. M. (2005). Epigenetic overlap in autism-spectrum neurodevelopmental disorders: MECP2 deficiency causes reduced expression of UBE3A and GABRB3. Hum Mol Genet, 14(4), 483-492. doi: 10.1093/hmg/ddi045 
Sebat, J., Lakshmi, B., Malhotra, D., Troge, J., Lese-Martin, C., Walsh, T., Wigler, M. (2007). Strong association of de novo copy number mutations with autism. Science, 316(5823), 445-449. doi: 10.1126/science.1138659

Skuse, D. H. (2007). Rethinking the nature of genetic vulnerability to autistic spectrum disorders. Trends Genet, 23(8), 387-395. doi: 10.1016/j.tig.2007.06.003

Sousa, I., Clark, T. G., Toma, C., Kobayashi, K., Choma, M., Holt, R., .Monaco, A. P. (2009). MET and autism susceptibility: family and case-control studies. Eur J Hum Genet, 17(6), 749-758. doi: 10.1038/ ejhg.2008.215

St Pourcain, B., Wang, K., Glessner, J.T., Golding, J., Steer, C., Ring, S.M., Skuse, D.H., Grant, S.F., Hakonarson, H., and Smith, G.D. (2010). Am. J. Psychiatry. Published online July 15, 2010. 10.1176/appi. ajp.2010.09121789.

Vernes, S. C., Newbury, D. F., Abrahams, B. S., Winchester, L., Nicod, J., Groszer, M., Fisher, S. E. (2008). A functional genetic link between distinct developmental language disorders. N Engl J Med, 359(22), 2337-2345. doi: 10.1056/NEJMoa0802828

Volkmar, F. R. (2005). Handbook of Autism and Pervasive Developmental Disorders (3 ed.). New Jersey: John Wiley \& Sons.

Wang, K., Zhang, H., Ma, D., Bucan, M., Glessner, J. T., Abrahams, B. S., Hakonarson, H. (2009). Common genetic variants on 5p14.1 associate with autism spectrum disorders. Nature, 459(7246), 528-533. doi: 10.1038/nature07999

Wang K, Dickson SP, Stolle CA, Krantz ID, Goldstein DB, Hakonarson H. Interpretation of association signals and identification of causal variants from genome-wide association studies. Am J Hum Genet. 2010 May 14;86(5):730-42. Epub 2010 Apr 29.

Wang, L., Jia, M., Yue, W., Tang, F., Qu, M., Ruan, Y., .Zhang, D. (2008). Association of the ENGRAILED 2 (EN2) gene with autism in Chinese Han population. Am J Med Genet B Neuropsychiatr Genet, 147B(4), 434-438. doi: 10.1002/ajmg.b.30623

Yi, J. J., \& Ehlers, M. D. (2005). Ubiquitin and protein turnover in synapse function. Neuron, 47(5), 629-632. doi: 10.1016/j.neuron.2005.07.008

Zafeiriou, D. I., Ververi, A., \& Vargiami, E. (2007). Childhood autism and associated comorbidities. Brain Dev, 29(5), 257-272. doi: 10.1016/j.braindev.2006.09.003

Zhong, H., Serajee, F. J., Nabi, R., \& Huq, A. H. (2003). No association between the EN2 gene and autistic disorder. J Med Genet, 40(1), e4. 


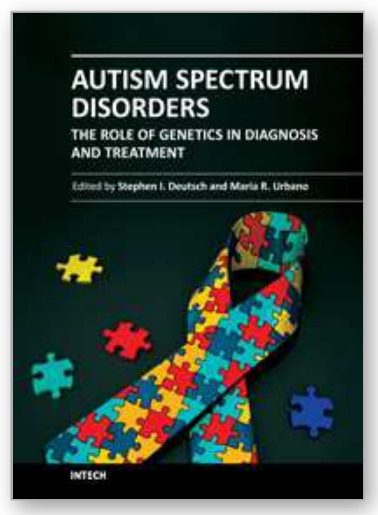

\author{
Autism Spectrum Disorders: The Role of Genetics in Diagnosis and \\ Treatment \\ Edited by Prof. Stephen Deutsch
}

ISBN 978-953-307-495-5

Hard cover, 198 pages

Publisher InTech

Published online 01, August, 2011

Published in print edition August, 2011

Estimated prevalence rates of autism spectrum disorders (ASDs) have increased at an alarming rate over the past decade; current estimates stand as high as 1 in 110 persons in the population with a higher ratio of affected males to females. In addition to their emotional impact on the affected persons and their family members (in fact, the latter are often unrecognized unaffected â€œpatientsâ€ themselves), the economic and social impacts of ASDs on society are staggering. Persons with ASDs will need interdisciplinary approaches to complex treatment and life planning, including, but not limited to, special education, speech and language therapy, vocational skills training and rehabilitation, social skills training and cognitive remediation, in addition to pharmacotherapy. The current book highlights some of the recent research on nosology, etiology, and pathophysiology. Additionally, the book touches on the implications of new research for treatment and genetic counseling. Importantly, because the field is advancing rapidly, no book can be considered the final word or finished product; thus, the availability of open access rapid publication is a mechanism that will help to assure that readers remain current and up-to-date.

\title{
How to reference
}

In order to correctly reference this scholarly work, feel free to copy and paste the following:

John J.M. Connolly and Hakon Hakonarson (2011). The Genetics of Autism Spectrum Disorders, Autism Spectrum Disorders: The Role of Genetics in Diagnosis and Treatment, Prof. Stephen Deutsch (Ed.), ISBN: 978-953-307-495-5, InTech, Available from: http://www.intechopen.com/books/autism-spectrum-disorders-therole-of-genetics-in-diagnosis-and-treatment/the-genetics-of-autism-spectrum-disorders

\section{INTECH}

open science | open minds

\section{InTech Europe}

University Campus STeP Ri

Slavka Krautzeka 83/A

51000 Rijeka, Croatia

Phone: +385 (51) 770447

Fax: +385 (51) 686166

www.intechopen.com

\section{InTech China}

Unit 405, Office Block, Hotel Equatorial Shanghai

No.65, Yan An Road (West), Shanghai, 200040, China

中国上海市延安西路65号上海国际贵都大饭店办公楼 405 单元

Phone: +86-21-62489820

Fax: +86-21-62489821 
(C) 2011 The Author(s). Licensee IntechOpen. This chapter is distributed under the terms of the Creative Commons Attribution-NonCommercialShareAlike-3.0 License, which permits use, distribution and reproduction for non-commercial purposes, provided the original is properly cited and derivative works building on this content are distributed under the same license. 